\title{
Review
}

\section{Development and evaluation of the management of the neuropathic bladder}

\author{
JJ Wyndaele \\ Department of Urology and Center for Urological Rehabilitation, University of Antwerp, Belgium
}

Keywords: spinal cord injury; neuropathic bladder; catheterisation; urology

The history of the development of the urological management of the neuropathic bladder in spinal cord injury (SCI) patients is both an important and interesting subject though its major part is fairly recent and thus still short.

Little is known about SCI in ancient times, but there is no doubt that most or all SCI patients would have died very soon after injury. The Smith Surgical Papyrus is frequently quoted in this connection: it describes SCI as an ailment not to be treated. ${ }^{1}$ This does not exclude that somewhere, someone may have started to catheterise a spinal paralysed master or relative. Urinary catheters have indeed been used for more than 5000 years. $^{2}$

However, through the last century and the first part of this century, SCI meant an early death. Gradually physicians began to appreciate the importance of urological treatment when they found that urinary problems were amongst the main threats to life.

In 1833 Curling described in the London Medical Gazette how he had noticed that in SCI patients urinary retention, bladder distension and overflow incontinence occurred. ${ }^{3} \mathrm{He}$ proclaimed that it was necessary to drain the bladder with a catheter, but admitted that in any event, urinary infection and sepsis would lead the patient to an early end.

During the disastrous World War I, medical services were confronted with large numbers of patients with spinal trauma. Rules for proper bladder management were proposed. Cystostomy or manual bladder expression were presented as alternatives to transurethral catheterisation. ${ }^{4-6} \mathrm{But}$ the final outcome for the patient remained unchanged.

Between the Wars tidal drainage, derived from Laver's automatic bladder irrigator, ${ }^{7}$ was propagated again. ${ }^{8}$ The continuous bladder rinse, the rhythmic filling and emptying were meant to lower the incidence of severe urinary infection and to promote early recovery of bladder function, but its use was difficult and problems frequently occurred.

During World War II, a dramatic change in SCI treatment arose from the efforts of a few men, among whom the leaders were Sir Ludwig Guttmann and Donald Munro. By developing and installing comprehensive patient management, they succeeded in proving that SCI patients, when properly treated and rehabilitated, were often able to return to their family and into society where they could live a valuable and gratifying long life. Very important in this management, was the proper treatment for the spinal shock bladder from the postinjury period. By 'non touch' intermittent transurethral catheterisation (IC) and the use of antibacterial drugs, the rate of urinary tract infection and urinary sepsis could be substantially lowered. ${ }^{9}$ During the following 20 years, this message spread slowly but surely throughout the world.

A little later, clean intermittent self-catheterisation was proposed for different kinds of bladder retention. ${ }^{10}$ It was used for SCI patients during spinal shock, also for the longer term treatment. Despite this evolution, the morbidity of urological-nephrological pathology continued to remain high for some time. Chronic pyelonephritis, kidney stones, amyloidosis and secondary hypertension were still among the leading causes of death after SCI in the late sixties and early seventies. ${ }^{11-13}$

But knowledge increased and methods for the accurate diagnosis and the optimal treatment gradually improved. As a result, urological complications no longer had their dubious first place amongst the causes of mortality from the late $70 \mathrm{~s}$, at least for those patients who were treated and followed up in a comprehensive way.

Today, many basic data are known about lower urinary tract physiology and about the pathophysiology caused by a spinal cord lesion. In the acute period of spinal shock, proper bladder drainage by IC is used by most doctors; others prefer a fine bore cystostomy, and a few still use indwelling transurethral catheters. Without doubt, it is best not to leave a catheter in for a long period. If an indwelling drainage is necessary, complications can be limited by strict catheter care. The importance of a team approach to urinary bladder management has been stressed. ${ }^{14}$ 
Following the spinal shock period, a clear diagnosis of bladder-urethral function has to be made. This can be done by clinical studies, but urodynamic investigation is better. Also in SCI patients, efficient lower urinary tract function means a good interaction of the detrusor and sphincter. ${ }^{15}$ Dysfunction of either structure and dyssynergic activity between them can be readapted into a dynamically safe unit which permits sufficient continence and reliable micturition in the majority of patients. The basic rehabilitation techniques - suprapubic tapping for the upper motoneuron (UMN) type and or straining/Crédé for the lower motoneuron (LMN) type of neuropathic bladdercontinue to be useful, but it is necessary to follow the urodynamic evolution closely.

Pharmacotherapy can be of great help. ${ }^{16}$ Intermittent catheterisation (IC) has gained great popularity now also for long term treatment. It is used in LMN lesions and in combination with detrusor relaxing drugs for those with UMN lesions. Long term results have been described and would seem to be satisfactory.

For some patients, despite treatment by the methods described above, results remain poor. They continue to have severe incontinence and/or retention. Their urodynamic parameters may indicate danger for the upper urinary tract. Chronic or recurrent urinary tract infection may occur. In these patients, other forms of treatment require to be used.

To increase bladder capacity and lower the intravesical pressure in the presence of a hyperreflexic or a hypocompliant detrusor, bladder augmentation or substitution with bowel segments can be performed. The late results and complications have to be carefully evaluated, especially as some studies would suggest an oncological risk. To cure outlet obstruction, incision or resection of the external sphincter and/or the bladder neck can be done. The technique of sphincterotomy, originally described by Cosbie Ross (1956), is still used with different variations proposed by different authors. ${ }^{17}$ Permanent and non-permanent urethral stents may become a valuable alternative procedure.

When the urethral pressure is very low and severe stress urinary incontinence occurs in a patient with a large flaccid urinary bladder, urethral resistance can be increased by different means. A penile clamp is rarely used nowadays because it endangers the urethra and the penile skin by causing pressure ulcers. The implantable artificial sphincter has found its well defined indications. ${ }^{18}$ For symptomatic treatment of urinary incontinence in the male patient, a condom sheath with a collecting bag has been in use for a long time and the modern disposable types which are glued to the penile shaft have become very popular. ${ }^{19}$

One of the main problems of urological treatment concerns incontinent tetraplegic women. When intermittent catheterisation is not possible or practical, it is often necessary to use an indwelling catheter. But innovations have appeared, such as the use of electronic means to control urinary voiding and continence and they offer a very valuable alternative form of treatment in selected patients. ${ }^{20-22}$
Urinary diversions such as an ileal conduit or a cutaneous ureterostomy are much less frequently used than they were some 30 years ago. This is partly due to better primary diagnosis and better primary treatment, with a resulting lowering of the incidence of severe renal complications. But regular follow-up also plays an important role as it permits the discovery of complications or of dangerous dynamic conditions at an early stage.

To conclude, an important change has occurred in the urological management of SCI patients during the past 50 years.

In 1979 Herbert Talbot warned that 'we have come to the end of the beginning. It is time to start to consolidate our gains and bring the message to our colleagues'. In 1995, this would appear to have been in the main achieved, but our efforts must continue. The evolution in urological management will go on. It remains to be seen what the next century will bring.

Looking back, one feels permitted to say: 'a nice job has been done'. Looking to the future one can add: 'but there is still a lot to achieve'.

\section{References}

1 Talbot HS. The holistic approach to spinal cord injury. Paraplegia 1979; 17: 32-35.

2 Brosman SN. History of the urethral catheter. J Wadsworth Gen Hosp 1965; 8: 93-98.

3 Curling TB. Essay on affections of the bladder in paraplegia. London. Med. Gaz. 1833; 13: 78-80.

4 Besley FA. A plea for the non catheterization of the urinary bladder in cases of gunshot wounds of the spinal column. JAMA 1917; 69: 638-639.

5 Hugonet $\mathrm{P}$, Dejerine M. Les grands infirmes par troubles des centres nerveux. Extrait de conférence interalliée pour l'étude de la rééducation professionelle et des questions qui intéressent les invalides de guerre. Grand Palais Paris 1917. Imprimerie Choix, 3.

6 Vellacott PN. Spinal injury with retention of urine. The avoidance of catheterization. Lancet 1919; 733-737.

7 Laver $\mathrm{CH}$. The automatic bladder irrigator. Guy's Hosp Gaz 1917; 31: 71.

8 Munro D, Hahn J. Tidal drainage of the urinary bladder $N$ Engl J Med 1935; 212: 229-237.

9 Guttmann L, Frankel $\mathrm{H}$. The value of intermittent catheterization in the early management of traumatic paraplegia and tetraplegia. Paraplegia 1966; 4: 63-83.

10 Lapides J, Diokno A, Silber S, Lowe B. Clean intermittent self-catheterization in the treatment of urinary tract disease. J Urol 1972; 107: 458-461.

11 Tribe CR, Silver JR. Renal Failure in Paraplegia. Pitman Medical Publishing Company: London, p 107.

12 Hackler RH. Longterm suprapubic cystostomy drainage in spinal cord injury patients. Br J Urol 1982; 54: 120-121.

13 Warren JW, Muncie HL Jr, Bergquist EJ, Hoopes JM. Sequelae and management of urinary infection in the patient requiring chronic catheterization. $J$ Urol 125: 1-8.

14 Lindan R, Leffler E, Freehafer AA. The team approach to urinary bladder management in spinal cord injury patients: a 26 year retrospective look at the Highland View Hospital Urinary Catheter Care Team. Paraplegia 1990; 28: 314-317.

15 Madersbacher $\mathrm{H}$. The various types of neurogenic bladder dysfunction: An update of current therapeutic concepts. Paraplegia 1990; 28: 217-229.

16 Wyndaele JJ. Review article. Pharmacotherapy for urinary bladder dysfunction in spinal cord injury patients. Paraplegia 1990; 28: 146-150. 
17 Cosbie Ross J, Gibbon NOK, Damanski M. Division of the external urethral sphincter in the treatment of the paraplegic bladder: a preliminary report on a new procedure. Paraplegia 1987; 25: 185-195.

18 Light JK. Use of the artificial urinary sphincter to achieve continence in patients with a spinal cord injury. Paraplegia 1984; 22: 50.

19 de Leval J, Louis JC. A new aid in the management of urinary incontinence in male paraplegic patients. Paraplegia 1978-1979;
16: 299-302.

20 Arnold EP. Innovations and future possibilities. In: Parsons K, Fitzpatrick J (eds). Practical Urology in Spinal Cord Injury. Springer Verlag: London, pp 121-140.

21 Brindley GS. The first 500 patients with sacral anterior root stimulator implants: general description. Paraplegia 1994; 32: 795-805.

22 Brindley GS. The first 500 sacral anterior root stimulators: implant failures and their repair. Paraplegia 1995; 33: 5-9. 